\title{
AS RANHURAS DA NATUREZA HUMANA EM "PAI CONTRA MÃE", DE MACHADO DE ASSIS
}

\author{
THE CRACKS OF HUMAN NATURE IN "PAI CONTRA MÃE", \\ BY MACHADO DE ASSIS
}

\author{
Raquel Cristina Ribeiro Pedroso \\ Universidade Estadual Paulista, São Paulo, São Paulo, Brasil \\ ra.ribeirop@gmail.com \\ Gabriela Kvacek Betella \\ Universidade Estadual Paulista, São Paulo, São Paulo, Brasil \\ kvacek.betella@unesp.br
}

Resumo: Considerando a constituição do sujeito moderno na obra machadiana, objetiva-se analisar a representação de pulsões humanas no conto "Pai contra mãe", publicado na coletânea Relíquias de Casa Velha, de 1906, por Machado de Assis. O conto citado abrange aspectos da moralidade que entrelaçam instintos de crueldade e natureza do mal como parte congênita da formação do entorno social. Pretende-se descrever a reificação do homem pela escravidão em meio à luta de autopreservação e tendências da alma para a percepção de caminhos possíveis frente a situações de ameaça.

Palavras-chave: Machado de Assis; Moral; Pulsões humanas; "Pai contra mãe"; Escravidão

Abstract: Considering the constitution of the modern subject in Machado's books, with objective to analyze the representation of human drivers in the short story Father against Mother, "Pai contra mãe", published in the collection Relíquias de casa velha, from 1906, by Machado de Assis. The aforementioned tale covers aspects of morality that interweave instincts of cruelty and the nature of evil as a congenital part of social formation. It is intended to describe the reification of man by slavery in the midst of the struggle for self-preservation and soul tendencies for the perception of possible paths in the face of threatening situations. Keywords: Machado de Assis; Moral; Human drivers; "Pai contra mãe"; Slavery 


\section{Introdução}

O Rio de Janeiro novecentista era um aglomerado de costumes, modos e interesses, e por isso tem em Machado de Assis um receptáculo diferenciado no tocante à representação literária brasileira, quanto à constituição física e psicológica de personagens e às suas relações com o entorno social. O mundo machadiano é essencialmente o mundo da cidade, dos costumes da corte carioca, da escrita humorística aos moldes do século XIX, de personagens com caracteres que se aproximam dos convivas de saraus e cafés da rua do Ouvidor. Essa aproximação evidencia o olhar do autor para aspectos públicos e privados das relações dos indivíduos e, de modo sensível, imprime notas de renovação estética das formas de arte na tomada de consciência. Além disso, o modo machadiano de representar a sociedade de seu tempo e lugar carreia elementos da historiografia, que é feita de dados humanos - logo, a subjetividade e as pulsões daqueles que viveram e estão personificados em relatos históricos incorporam-se ao relato ficcional. Essa indicação do papel das artes na constituição de uma identidade é fator decisivo para examinar a literatura de Machado de Assis em seu tempo.

A escrita de Machado é um agente mobilizador de memórias capaz de instigar correntes de pensamentos que perpassam acontecimentos fugidios, tensões políticas e o ínfimo da interioridade do sujeito. A subjetividade do homem de seu tempo, constituída do gosto europeu plasmado ao Brasil, moldava-se às experiências de um país escravocrata às voltas com a nova república. Machado localizou esse homem entre a crítica mordaz e a benevolência; entre a ironia, o humor, as pulsões próprias da autoconservação, e o questionamento moral acerca dos males que há dentro de cada um que se afirmam arraigados nas conjunturas sociais.

O leitor assiste aos conflitos da segunda metade do século XIX, como a guerra do Paraguai, os debates sobre a escravidão, o republicanismo, a guerra de Canudos, entre outros fatos, em contos e crônicas que cobram retratação político-social num arranjo literário dos mais elaborados, entretanto, com tom de descompromisso que não desagradava a imprensa sensacionalista. Na elaboração de Machado, a junção entre o macio e o duro de uma escrita que ora parece empolada beirando a erudição agressiva, ora se faz de ironia e escárnio, quase indiferente à barbárie, atesta para a crítica recoberta nas linhas de um pessimista-esclarecido que problematiza a realidade de seu tempo pelo riso.

Neste este artigo propomos a leitura do conto "Pai contra mãe", de 1906, para a percepção do modo pelo qual Machado de Assis, comprometido em retratar a constituição moral do sujeito em situação de conflito, faz do conto um paradoxal tratado político e humano. A representação que Machado faz de pulsões humanas como parte congênita das estruturas sociais se faz por meio de personagens em situações de ameaça. Noutras palavras, o autor brasileiro, hábil em combinar em seu modo de representação o alcance universal das questões da alma com a matéria social de seu meio, escolhe costumeiramente as situações-limite para suas personagens manifestarem comportamentos em ambas as direções, de modo ajustado, sem excessos e indissoluvelmente ligado às imposições do conflito social brasileiro. Assim, pretendemos ressaltar os caminhos pautados pela busca de autoconservação e por meio dos quais a natureza do mal e o instinto de sobrevivência fazem aflorar as pulsões humanas do indivíduo que, desde o Gênesis, tende à perversidade. 


\section{O cerco de Cândido Neves}

Os costumes e formas de combinação social do sujeito presentes na corte fluminense da virada do século XIX para o XX, têm em personagens de Machado de Assis o retrato da pessoa humana, da moralidade e das relações possíveis entre as estruturas que moldam o público e o privado. Em meio a esse ambiente ficcional, sob o rescaldo da escravidão, Cândido Neves se reconhece como agente de manutenção da lei, da ordem, da livre circulação dos proprietários e suas mercadorias, apesar de estar em um patamar nada distante do negro fugido em busca da liberdade de existência. Cândido Neves, cujos nome e sobrenome reforçam a ideia de brancura, encontra uma ocupação após tentar várias empresas, tornando-se caçador de escravos fugidos. O primeiro nome e seu apelido natural, Candinho, estabelecem uma relação de oposição com o significado do ofício e, sobretudo, com a descrição da atitude que enforma o episódio central do conto. Se o significado de cândido é, por extensão, ligado à pureza ou ingenuidade, e os atos de Candinho nada têm de brandos, ingênuos ou cheios de candura, podemos perceber de antemão a estrutura que Machado prepara para a construção da trama, levando em conta as circunstâncias sob as quais o protagonista toma a atitude capital.

"Pai contra mãe" é parte da coletânea de contos Relíquias de Casa Velha (1906), publicado por H. Garnier, Livreiro-Editor das obras de Machado. O livro traz na Advertência um chamamento para uma leitura atenta e desprendida do que virá ao dobrar das páginas. Comparando sua vida a uma casa - com "[...] lembranças de um dia ou de outro, da tristeza que passou, da felicidade que se perdeu" (ASSIS, 2015, p. 620), o autor deixa a explicação sobre o título nas mãos do leitor, sob a justificativa de que são ideias, histórias, críticas e diálogos impressos nas relíquias narrativas de seu tempo.

O conto apresenta uma divisão estrutural que formaliza os cinco primeiros parágrafos sob o espólio da escravidão, dos ofícios e aparelhos apresentados ao leitor em tom de crônica, ou de narrativa descomprometida com o incômodo que a sociedade mantinha ao pactuar com a escravidão. Os parágrafos seguintes apresentam a história de uma fuga e a ação de Cândido Neves, quase em um lembrete para o leitor do que foi relatado nos primeiros parágrafos do conto. Ao unir as duas estruturas, Machado faz uso do exemplum, um artifício ficcional conhecido desde as narrativas medievais para ilustrar o que era pregado em discursos e sermões religiosos, dado próprio de histórias de matiz moralizante.

"Pai contra mãe" tem início com um narrador apresentando a escravidão como instituição social, bem como os aparelhos ligados ao ofício de manter os escravos sob controle como necessários à ordem. Usava-se o ferro ao pescoço, o ferro ao pé e a máscara-de-flandres, esta "[...] tinha só três buracos, dois para ver, um para respirar, e era fechada atrás da cabeça por um cadeado" (ASSIS, 2015, p. 621). O ferro ao pescoço aplicado ao escravo fujão, semelhante a uma coleira, servia mais para o reconhecimento de fugas reincidentes do que propriamente como castigo; se havia fuga, havia justificativa para o uso de tais "aparelhos" e "ofícios". A máscara, tão grotesca quanto a ordem social, que não se pode alcançar sem certo grau de crueldade, prometia extinguir dois pecados e fazer nascer duas virtudes: a sobriedade e a honestidade - com a máscara os escravos eram libertos da embriaguez e da tentação de furtar. A ironia do narrador em sugerir que os negros poderiam gostar da escravidão e que os fins justificariam os meios pela repetição das fugas e perdas por parte dos proprietários exemplifica o escárnio com o qual Machado descreve a natureza humana em meio ao desmascaramento do gosto pelo mal presente nas ranhuras sociais: 
Eram muitos [os escravos], e nem todos gostavam da escravidão. Sucedia ocasionalmente apanharem pancada, e nem todos gostavam de apanhar pancada. Grande parte era apenas repreendida; havia alguém de casa que servia de padrinho, e o mesmo dono não era mau; além disso, o sentimento da propriedade moderava a ação, porque dinheiro também dói. (ASSIS, 2015, p. 621).

Divulgados como mercadorias, com características e traços físicos estampados à entrada das vendas, pegar negros fugidos representava um trabalho comum e até um "nobre ofício" pela aparência de cumprimento da lei, que resguardava o dono de senzala diante da perda de seu bem, e pelo valor da gratificação a ser recebida. Além da inaptidão para o trabalho ou o acaso dos dias, outro motivo para a escolha de tal ofício residia no gosto de servir, ainda que por vias inescrupulosas, o impulso moral de ser parte da ordem. "[...] Pegar escravos fugidios era um ofício do tempo. Não seria nobre, mas por ser instrumento da força com que se mantêm a lei e a propriedade, trazia esta outra nobreza implícita das ações reivindicadoras" (ASSIS, 2015, p. 621). Cândido Neves, o Candinho, após tentar muito ofícios rendeu-se à competição acirrada na busca por recompensas pela captura de fugidos. Se o protagonista toma uma atitude extrema, também podemos pensar na sua pouca ou nenhuma especialização em ofícios, além da ausência de vontade de aprendê-los, conduta que procurava justificativa por meio do sentido que a nova função adquiria. Cândido tentava provar a razão do pouco caso que tinha com o trabalho com alto valor de ser capitão do mato.

Candinho apaixonou-se por Clara (o nome da moça implica em mais um elemento branqueador aliciado pelo protagonista), casou-se, foram morar com tia Mônica e tiveram um filho. A tia de Clara, percebendo que a necessidade batia à porta, tentou abrir os olhos do casal para a falência antecipada dos planos de paternidade. Cândido Neves gloriava-se da fama de caçador de escravos e tinha nisso a esperança de dias melhores. Pegar fugidos "só exigia força, olho vivo, paciência e um pedaço de corda" (ASSIS, 2015, p. 623). Após ler os anúncios, "[...] copiava-os, metia-os no bolso e saía às pesquisas. Tinha boa memória. Fixados os sinais e os costumes de um escravo fugido, gastava pouco tempo em achá-lo, segurá-lo, amarrá-lo e levá1o" (ASSIS, 2015, p. 623). Candinho se fez ágil e forte, ficava nas esquinas à espreita, e na menor semelhança de um passante com um escravo, deixava os convivas e ia atrás do fugitivo até a captura: "nem sempre saía sem sangue, as unhas e os dentes do outro trabalhavam, mas geralmente ele os vencia sem o menor arranhão" (ASSIS, 2015, p. 624).

Os princípios que estruturam a obra literária, segundo Antonio Candido (2010, p. 40) perpassam o sentimento de realidade, pressupõem o dado real na ficção, mas não dependem dele, e sim dos mediadores que estruturam a obra e graças aos quais tornam coerentes a duas séries, a real e a fictícia. Machado dialogou com minuciosas questões sociais de seu tempo, numa tentativa de expor elementos do entorno da corte carioca e isso contribuiu para que ele se tornasse um exímio produtor literário. José Luiz Passos (2007, p. 51) reitera que a escrita de Machado proporcionou uma mudança de "ênfase no cenário para uma atenção maior à construção das motivações dos protagonistas; uma passagem da relação que o sujeito tem com a matéria em redor à relação que ele estabelece com os demais”. Nesse sentido, a narrativa ainda poderia fecundar o cotidiano da nação de forma épica ou trágica, mas mantendo a peculiaridade de indivíduos e grupos sociais. Relações e elementos exteriores seriam interiorizados e agiriam como parte da composição do humano - a literatura discorrendo sobre o modo como o sujeito guia sua vida e como consegue domínio sobre o outro. Assim, o dado real - indivíduos que já nasciam e cresciam na estrutura de opressão, possibilita à literatura problematizar a escravidão como um dos males arraigados ao Império brasileiro. 
"Pai contra mãe" é parte das linhas fiadas que Machado de Assis usou em contos escritos em épocas muito diferentes, pelo menos de 1885 a 1906, como "O enfermeiro" (1896), "Pílades e Orestes" (1906), "O caso da vara" (1891) e "A causa secreta" (1896), para costurar o que Alfredo Bosi (2007) chama de o fio negro do mal: extremos da natureza humana percebidos em personagens aos moldes reais, numa espécie de acordo entre o eu e o ambiente externo. Essa dualidade entre condutas pessoais e a sociabilidade encontra ecos na paisagem composta pelo sistema que incentiva o perseguidor a perseguir. Quando chegou a escassez de escravos fugidos e assim também o lucro de Candido Neves, o instinto da autoconservação levou-o ao extremo de si - o filho prestes a nascer, cinco dias para suprir os aluguéis atrasados e tia Mônica insistindo que entregasse a criança à Roda dos enjeitados.

Machado instiga pontos da natureza humana no leitor para o pêndulo que se estabelece durante o conto: de um lado, não bastava ser o filho desejado no casal, era um menino, e, ambos os pais desejavam justamente este sexo; de outro, era preciso abandoná-lo. Há um fio narrativo que se constrói com vistas à relativizar os atos dos homens livres em relação aos prisioneiros, que, segundo Alfredo Bosi (2007, p. 125) se faz por uma perspectiva que é "[...] a da contradição que se despista, do terrorista que se finge diplomata. É preciso olhar para a máscara e para o fundo dos olhos que o corte da máscara permite às vezes entrever. Esse jogo tem um nome bem conhecido: chama-se humor".

O humorismo em Machado faz com que as ações sejam "aceitáveis" diante das circunstâncias, funciona como modelagem da forma humana realizada pela aparência social institucionalizada. No lugar do julgamento de comportamentos, da utopia de exemplificação moral, do que seria de bom-tom social, há a corrosão do eu e do moralismo. As bases humanas permanecem flutuantes em torno do elo indissociável com o mundo interior, com a sobreposição de máscaras e o uso proveitoso que se pode ter das mesmas. A vida em sociedade não aceita subjetividades, peculiaridades ou verdades individuais - antes, busca generalizações de comportamentos. O privado é subjugado pelo público, no qual se encontra a degradação, imprudência e frivolidades. O que livraria o homem de tais caprichos e/ou loucuras?

O sentimento do contrário conceituado por Luigi Pirandello (1986) no ensaio "L'umorismo", de 1908, retrata experiências narrativas que têm na inquietude, no fastio por situações comuns, o mote para a afirmação da individualidade. Artifícios como humorismo, ironia e análise incisiva e mordaz da natureza humana agem como espelho da mentalidade decadente da segunda metade do século XIX e início do século XX. O humorismo pirandelliano é um conceito muito particular e renovador das visões sobre o humor, e que apresenta alguns pontos de contato com a particular ironia machadiana, que não se enquadra nos propósitos filosóficos convencionais. A ideia de que alguém está rindo durante as cenas narradas é pertinente na medida em que o leitor é capaz de vivenciar os sentimentos opostos e a intensidade da convivência entre eles, vale dizer, entre a aparência dos fatos e a realidade dos mesmos, entre as convenções sociais e a identidade do sujeito. É preciso lembrar que Pirandello estava preocupado com uma abordagem sobre as formas de representação artística do humor, e menos interessado nos conceitos filosóficos, daí uma concepção que se distancia da ironia tradicionalmente regida pela filosofia.

Pinrandello na Itália, com Il fu Mattia Pascal, de 1904, e Machado de Assis no Brasil, décadas anteriores com as Memórias Póstumas de Brás Cubas (1880-81) e os contos de Papéis Avulsos (1882), percebem a condição esvaziada do sujeito e o contraste com os anseios contemporâneos e elaboram narradores que conduzem os protagonistas por caminhos designados pelo papel social possível. O leitor machadiano pode conceber a construção de Brás 
Cubas como o modelo de falsificação de convenções humanas, entretanto, uma falsificação necessária, pois somente a partir dela se tem a dimensão de que viver sem convenções significa já estar morto. Estamos diante de um teatro da existência que compreende ultrajes, falseamento, tom provocativo e ao mesmo tempo complacente.

No conto de 1906, Machado concebe motivos díspares de situações humanas revistas pelo humorismo como um sentir e ressentir a agonia dos contrastes - quase um tratado em que o leitor, apresentado a um jogo de forças dentro do qual o escravo é escravo, reconhece ser esse o motivo que a sociedade se utiliza para retirar do cativo a chance de ter outra história, para além daquela que lhe impuseram quando o compraram como mercadoria. Candinho, ao rever o jornal, identifica o anúncio de uma certa escrava fugida: tratava-se de Arminda, a negra mais procurada das redondezas. Necessitando levar o filho à roda dos enjeitados saiu em direção à Rua dos Barbonos. E qual não foi a surpresa, ao fim de uma perambulação com a criança nos braços, encontrar o objeto de sua procura.

A caçada estava, de fato, em vistas de acontecer. O personagem apressou-se em chegar perto da negra e conferir se era mesmo a mulata fujona:

\begin{abstract}
Arminda voltou-se sem cuidar malícia. Foi só quando ele, tendo tirado o pedaço de corda da algibeira, pegou dos braços da escrava, que ela compreendeu e quis fugir. Era já impossível. Cândido Neves, com as mãos robustas, atava-lhe os pulsos e dizia que andasse. A escrava quis gritar, parece que chegou a soltar alguma voz mais alta que de costume, mas entendeu logo que ninguém viria libertá-la, ao contrário. Pediu então que a soltasse pelo amor de Deus. (ASSIS, 2015, p. 626).
\end{abstract}

Cândido Neves, cujo nome é parte da teia entretecida de riso, ironia e escarninho, é o homem juridicamente livre, pobre e dependente, mas que pela condição de cor, não percebe que está apenas um degrau acima do escravo (BOSI, 2007, p. 86). Fruto da ilusão do patriarcado, da ideia generalizada de que por ser branco e livre poderia escalar a pirâmide do proprietário, age de modo a exalar crueldade intrínseca à luta que considerava necessária.

A esperança de um se tornou a desgraça do outro. Em meio à luta, súplicas e gemidos, Cândido Neves arrasta Arminda grávida pelas ruas ao olhar de quem passava ou estava à porta; todos compreendiam se tratar de mais uma captura, dentro da norma social. "Arminda ia alegando que o senhor era muito mau, e provavelmente a castigaria com açoites, - coisa que, no estado em que ela estava, seria pior de sentir" (ASSIS, 2015, p. 627). No ato de restituição da presa, a escrava aborta o filho diante de seu senhor e dos olhos de Candinho que, após receber a gratificação, retorna para casa com o filho nos braços.

O fruto de algum tempo entrou sem vida neste mundo, entre os gemidos da mãe e os gestos de desespero do dono. Cândido Neves viu todo esse espetáculo. Não sabia que horas eram. Quaisquer que fossem, urgia correr à Rua da Ajuda, e foi o que ele fez sem querer conhecer as consequências do desastre. (ASSIS, 2015, p. 627).

"Pai contra mãe" é um testemunho da moralidade que rege atos de vilania com a aparência de civilidade e os mantém no mesmo nível, inclusive quanto à intensidade; a desumanização veste-se da luta pela autopreservação. Se Arminda permanecesse em liberdade, não haveria a gratificação pelo serviço prestado, logo, o filho de Candinho seria entregue à roda dos enjeitados; se a captura fosse efetivada, a perda do filho de Arminda seria coisa certa. A intensidade da equivalência vem representada na explicação que equaciona os sentimentos envolvidos nas atitudes de Candinho: "o pai recebeu o filho com a mesma fúria com que pegara a escrava fujona de há pouco, fúria diversa, naturalmente, fúria de amor" (ASSIS, 2015, p. 627). 
Machado considerava a literatura com a lucidez de quem via na formação da sociedade, no valor do status, nos meandros dos jogos de interesse a percepção da subjetividade. Há quem defenda a busca por delinear um perfil que entendesse a humanidade por meio das virtudes, do homem que cultiva bons sentimentos como o que se tem na aparência das protagonistas dos primeiros romances machadianos. No entanto, percebe-se que a virtude existente na fase inicial, a moralidade e a resiliência são levados a cabo desde as primeiras linhas de contos e romances da década de 1880 em diante. Roberto Schwarz (2012, p. 249) assegura que:

à primeira vista, Machado trocava uma esfera acanhada e provinciana por outra enfaticamente universal e filosófica, amiga de interpelações, apartes e dúvidas hamletianas, à qual aliás não falta a nota da metafísica barata, reencontrando o tom de província noutro nível mais letrado (um achado esplêndido e moderno). Note-se que nessa segunda maneira, a das grandes obras, o universo da primeira continuava presente, como substância anedótica - mas não só (SCHWARZ, 2012, p. 249).

A mudança de tom dos narradores de Machado, a partir de 1880, advém da relativização dos valores morais cultivados pelas personagens dos primeiros romances. $\mathrm{E}$ um dado destacável dessa orientação é a exploração de múltiplos pontos de vista. Nesse âmbito o leitor é cativado pela imparcialidade, numa conjuntiva de negação e julgamento. Aqui se constata adequadamente a particularidade do "discurso moral" de Machado de Assis.

Jon Elster (1999, p. 76) explica que, após Aristóteles, o entendimento mais solidificado a respeito das emoções humanas em arte veio com a leitura de mundo proposta pelos moralistas franceses (séculos XVII e XVIII) - preocupados em analisar as fraquezas humanas e os comportamentos gerados por elas. Aristóteles (385-323 a.C) já observara que a emoção seria fruto de acontecimentos externos que (acidentalmente ou propositadamente) agiriam sobre a interioridade do sujeito. E a forma pelo qual ocorreria essa ação seria por um gatilho disparado em situações em que o sujeito precisaria lutar pela autopreservação. $O$ gatilho acionaria tendências de comportamentos recobertos pela dinâmica do mascaramento.

A filosofia aristotélica, segundo Elster (1999, p. 77), não refletiu sobre o modo pelo qual as emoções afetam o julgamento de motivações pessoais; assim como também não delimitou o que tocaria indiretamente no comportamento, e, por meio de alterações mentais se repetiria em novos gatilhos. O filósofo discutiu a maneira pela qual a conduta pode ser afetada a partir de estímulos externos ao sujeito. Assim, direcionamos nosso olhar para o modo pelo qual os gatilhos, quando acionados, desencadeiam os comportamentos. Esses fatores externos, sejam eles sociais, econômicos ou culturais imprimem no sujeito a conduta a ser usada em determinados círculos de convivência, então, temos as pulsões em execução.

Segundo Otto Maria Carpeaux (2014), embora os russos, os ingleses e os alemães sejam moralistas, em francês a palavra moralista tem outro sentido, "[...] significa um homem que observa insubornavelmente as fraquezas humanas [...]" (CARPEAUX, 2014, p. 5). Para o crítico, Gustave Flaubert foi um moralista assim: um meticuloso observador da realidade. E para os familiarizados com o enredo de Madame Bovary (1857) e Educação Sentimental (1869), não estará distante a associação da teoria moralista com o realismo na forma romance. A aptidão por perceber mundos interiores o fez elaborar os caminhos dos personagens que mais se assemelham a teias de acasos. Para Karl Heinz Bohrer (2001, p. 14), os moralistas eram pessimistas e subversivos quanto à moral conservadora ou convencional, ansiavam pelo desvendamento de trivialidades morais como o autoengano do ser humano. Embora tenham se firmado no campo de análise que não mais pautava o comportamento do homem por leis de 
alguma divindade superior, foi no estudo do Ser a partir de pulsões interiores da alma humana que encontraram terreno fértil para o desenvolvimento do pensamento.

Machado de Assis, no Brasil, em contos moralistas-sentenciosos ou na produção do absurdo que representa o realismo de perspectiva dúbia, propositadamente ambígua, deixou na literatura a anestesia social pós-colonialismo vivido pelo brasileiro. Após a década de 1880, manifestou uma espécie de fórmula que guardava e expunha (sem aparência de denúncia), a antinomia do sujeito - dualidade como parecer e ser, privado e público saíram do âmbito da moralidade e se uniram à máscara e ao desejo como natureza social. Logo, o aparente à sociedade e as pulsões dominadas pelo sujeito são parte de um mesmo $e u$.

Nesse contexto, lembremo-nos do conto "O espelho" (1882), escrito bem antes de "Pai contra mãe", em que Machado esboça uma teoria sobre a existência de duas naturezas; "duas almas", uma interior e a outra exterior, que juntas completariam o homem: "[...] quem perde uma das metades, perde naturalmente metade da existência; e casos há, não raros, em que a perda da alma exterior implica a da existência inteira" (ASSIS, 2015, p. 313). O peso dos impulsos na subjetividade de personagens sobre os quais a natureza age de modo a neutralizar a história (ainda que por pouco tempo), leva-os a processos de autoengano que, ora beiram ao cálculo, ora ao desvelamento da interioridade. O alferes de "O espelho" ou Cândido Neves de "Pai contra mãe" são impelidos a agarrarem-se ao que a natureza dispõe para a conservação da imagem de si diante do outro.

"O espelho" se engendra numa forma narrativa próxima aos contos de mistério para desvendar os fatos que cercam um protagonista que assume a narrativa para desaparecer assim que expõe, por meio da fábula, sua constatação de que ele próprio só existia com a imagem calculada (com o posto de alferes, com a farda) e refletida (nos outros, no espelho). O segundo exemplo ilustra um provável resultado do cálculo ao extremo, quando o protagonista é impelido à ação (que foi capaz de calcular) que justifica sua condescendência com as formas de violência que cometia, respaldadas pela violência do sistema no qual estava inserido. Gestos com essa equivalência de interesse, cálculo e consequente violência desmedida estão presentes em outros contos da fase madura de Machado, dos quais "O caso da vara" é, de fato, exemplar, pois coloca em situação um adolescente em formação, que pouco se importa com a surra que uma menina leva por causa da distração que ele provocou, e que lucra com a sua própria transigência.

O leitor de "Pai contra mãe" se percebe aturdido pelo tom de crônica presente no início do conto, pelo estilo documental do narrador ao falar dos aparelhos de combate aos escravos fugidos, da normatização da escravidão que era o fio negro do mal usado na teia da sociedade, na desumanização do outro. Quando o protagonista chega à casa com a gratificação nas mãos e o filho nos braços, tia Mônica aceita a criança, os cem mil-réis, e irmana-se ao pai que abraçava o filho salvo à Roda. A mulher "[...] disse, é verdade, algumas palavras duras contra a escrava, por causa do aborto, além da fuga. Cândido Neves, beijando o filho, entre lágrimas, verdadeiras, abençoava a fuga e não se lhe dava do aborto" (ASSIS, 2015, p. 627).

A sociedade assegurava que a culpa da crueldade direcionada à escrava era por sua condição de fugitiva. Isso culmina na ideia de Alfredo Bosi (2007) quando afirma que não havendo outro modo de assegurar-se no cotidiano, o sujeito só poderia tornar-se participante da norma social. E, agarrando-se às instituições, era-lhe resguardado "[...] o pleno direito à vida material e, daí, ao doce lazer que lhe permitirá até mesmo balançar-se naquelas cabriolas e fantasias [do pensamento]" (BOSI, 2007, p. 85). Entretanto, a justificativa para o que Cândido Neves realiza está mais para o instinto de crueldade em ação, entretecido pela busca de sobrevivência que o faz pensar "antes o filho dela, que o meu", que é a moralidade enegrecida 
pelo desejo do lucro e da vantagem, ou seja, pulsões da interioridade humana, que, em situações extremas agem como a natureza que avança sobre a história. Nesse processo, o que temos é a ação do sujeito que destina à tessitura do eu o disfarce de caráter, e assim, em meio ao mascaramento de interesses podemos reconhecer a dualidade do indivíduo e de suas pulsões.

\section{Considerações finais}

O conto apresenta o tema da fuga para problematizar o motivo da captura - serviço institucionalizado pela escravidão - para o qual a história de uma caçada nada é além de incidentes diários combatidos pelos proprietários. O embate de "Pai contra mãe" se faz pela instituição social que legitima a escravidão de seres humanos; se faz no cerco de Cândido Neves enquanto caçador de escravos fugidos. Se faz pela normatização da compra de pessoas em situação de mercadoria; se faz com o homem branco, pobre e livre que se autoengana pela condição do patriarcado. E, também se faz pela crueldade, instinto de autoconservação, luta por se manter acima da servidão, com pulsões humanas em extravasamento.

O narrador do conto, bem como os narradores de Machado, representa ambiguidades contidas em comportamentos sociais de forma sutil e aguda, como se desejasse que o leitor mirasse seu discurso e desistisse de ter esperança quanto a moralidade do homem. A inclinação à fraqueza de comportamento e a desorganização das pulsões governadoras das vontades agiriam como gatilhos para as ações de crueldade. Assim, o estilo de sua escrita, algo de um riso sutil, refinado, pronto ao embate polido, mantém a imparcialidade necessária para o retrato de emoções humanas, de modo que percebemos a presença de profunda morbidez, controlada pela narração como lampejos de serena manipulação.

A apresentação proposta por Machado de Assis em "Pai contra mãe" deixa claro - seja nos tempos da escravidão institucionalizada do século XIX ou nos dias atuais com a reificação do ódio -, que comportamentos baseados na hostilidade, no julgamento por generalizações, na busca pela supremacia de um ser contra seu semelhante, são efeitos do autoengano que se faz quando se quer revestir as pulsões mais sombrias da interioridade humana de bons sentimentos, ou mesmo da luta pela autopreservação. Não haveria solução, na cartilha de Machado, para a natureza humana e sua propensão aos instintos de domínio.

\section{Referências}

ASSIS, M. Obra completa em quatro volumes. São Paulo: Nova Aguilar, 2015.

BOSI, A. Machado de Assis: o enigma do olhar. São Paulo: Martins fontes, 2007.

BOHRER, K. H. O ético no estético. In: ROSENFIELD, Denis L. (org.) Ética e estética. Rio de Janeiro: Zahar, 2001.

CANDIDO, A. Dialética da malandragem. In: CANDIDO, A. O discurso e a cidade. Rio de Janeiro: Ouro sobre azul, 2010.

CARPEAUX, O. M. Prefácio. In: FLAUBERT, G. Madame Bovary. Tradução de Sérgio Duarte. Rio de Janeiro: Nova Fronteira, 2014. p. 05-14. 
ELSTER, J. Alchemies of the mind: rationality and the emotions. Cambridge University Press, 1999.

FLAUBERT, G. Madame Bovary. Tradução de Sérgio Duarte. Rio de Janeiro: Nova Fronteira, 2014.

FLAUBERT, G. Educação Sentimental. Tradução de Rosa Freire D'Aguiar. São Paulo: Penguin, 2017.

PIRANDELLO, L. L’umorismo. Milano: Oscar Mondadori, 1986.

PASSOS, J. L. Machado de Assis: o romance com pessoas. São Paulo: Edusp/Nankim, 2007.

SCHWARZ, R. Martinha versus Lucrécia: ensaios e entrevistas. São Paulo: Companhia das letras, 2012.

Recebido em: 01 de agosto de 2020 Aceito em: 13 de outubro de 2020 Publicado em dezembro de 2020 